\title{
Role of inflammatory cytokines in depression: Focus on interleukin-1ß (Review)
}

\author{
RAI KHALID FAROOQ ${ }^{1}$, KASHIF ASGHAR ${ }^{2}$, SHAHZINA KANWAL $^{3}$ and ALI ZULQERNAIN ${ }^{4}$ \\ ${ }^{1}$ Department of Physiology, Army Medical College, National University of Medical Sciences, Rawalpindi, \\ Punjab 46000; ${ }^{2}$ Department of Basic Sciences Research, Shaukat Khanum Memorial Cancer Hospital and \\ Research Centre (SKMCH \& RC), Lahore, Punjab 54000, Pakistan; ${ }^{3}$ Guangzhou Institutes of Biomedicine \\ and Health, Chinese Academy of Sciences, Guangzhou 510000, P.R. China; ${ }^{4}$ Department of Psychiatry and \\ Behavioral Sciences, Sargodha Medical College, University of Sargodha, Sargodha, Punjab 40100, Pakistan
}

Received August 29, 2016; Accepted October 6, 2016

DOI: $10.3892 /$ br. 2016.807

\begin{abstract}
According to the World Health Organization, major depression will become the leading cause of disability worldwide by the year 2030. Despite extensive research into the mechanisms underlying this disease, the rate, prevalence and disease burden has been on the rise, particularly in the industrialized world. Epidemiological studies have shown biological and biochemical differences in disease characteristics and treatment responses in different age groups. Notable differences have been observed in the clinical presentation, co-prevalence with other diseases, interaction with the immune system and even in the outcome. Thus, there is an increased interest in characterizing these differences, particularly in terms of contribution of different factors, including age, cytokines and immunotherapy. Research into the possible mechanisms of these interactions may reveal novel opportunities for future pharmacotherapy. The aim of the present review is to document recent literature regarding the impact of inflammatory mechanisms on the pathophysiology of the depressive disorder.
\end{abstract}

\section{Contents}

1. Introduction

2. Central and peripheral markers of inflammation in depression

3. Inflammatory cytokine concentration in depression

4. Data regarding the role of IL-1 $\beta$ in the pathophysiology of depression

Correspondence to: Dr Rai Khalid Farooq, Department of Physiology, Army Medical College, National University of Medical Sciences, Abid Majeed Road, Rawalpindi, Punjab 46000, Pakistan E-mail: kayfarooq@gmail.com

Key words: cytokines, depression, neuroinflammation, interleukin-1 $\beta$
5. Effects of IL-1 $\beta$ on neurogenesis

6 . Role of IL-1 $\beta$ in serotonergic metabolism

7. Receptors regulating IL-1 $\beta$ and their association with depression

8. Antidepressant therapy and variations in inflammatory cytokine concentration

9. Depressive-like behavior induced by chemotherapy

10. Cytokine-associated depressive symptoms and neurodegeneration

11. Neuroinflammation and its implication in the pathophysiology of depression

12. Conclusion

\section{Introduction}

Major depression is set to become the leading cause of disability worldwide by the year 2030 (1). The pathophysiology of depressive illness has been extensively investigated over the past decades and a wide range of underlying mechanisms have been identified for therapeutic interventions (2). Major theories revolve around alterations in neuroamine metabolism and efforts have been made to halt these alterations (3). The most recently identified drug group, selective serotonin reuptake inhibitors, are one such example. Yet the prevalence and disease burden, in terms of quality-adjusted life years lost to depression, are increasing globally. Inflammation has recently been considered as a contributory factor. However, it remains to be seen which of various inflammatory cytokines may be considered for use in intervention strategies. Interleukin (IL) $-1 \beta$ is one such factor with notable implications. The following review describes the existing evidence.

\section{Central and peripheral markers of inflammation in depression}

Depression has been associated with inflammatory markers since 1985 (4-7). Reduced numbers of red blood cells, hematocrit and hemoglobin, and increased reticulocyte number and changes in iron metabolism that are consistent with the inflammatory process have been observed in individuals 
presenting with major depressive illness. These observations are comparable with already established markers of inflammation (reduced levels of serum albumin and zinc) that are present during episodes of depression (8).

Research during the last two decades has revolutionized current understanding of depressive illness. Epidemiological studies have identified correlations between depression and degenerative, inflammatory, genetic, functional and various other types of disorder. Since Smith (9) presented a study of the implications of cytokines in depressive-like behavior, establishing the etiology and pathogenesis of depression has become a point of research. The majority of research has been dedicated to the co-prevalence of depression with vascular and inflammatory disorders. Numerous studies have reported these links and discussed their proposed mechanisms (10). Additionally, inflammatory disorders have been associated with alterations in behavior $(6,11)$. As a result of these findings, inflammation in general and its individual components (such as inflammatory cytokines), associated genes and their polymorphisms, as well as the effect of environmental interactions, have become a point of focus for future research.

Sickness behavior, first reported by Hart (12), was characterized by hyperthermia, lethargy, sleep and appetite disturbances, and reduced grooming, which arose as a consequence of an infectious stimulus. Many of these effects were later attributed to IL-1, one of a variety of pro-inflammatory cytokines that is released during the course of infection (10). It was reported in the same experiment that central administration of an antagonist effectively inhibited the above-mentioned behavioral effects in an animal in which IL-1 $\beta$ was injected intraperitoneally; however, hyperthermia and reduction in food-motivated behavior were not affected (13). Hart noted sickness behavior as an evolutionary strategy to fight disease-causing organisms. Yet the observed link between mood and inflammatory alterations led to the hypothesis that a bidirectional association between cytokines and behavioral alterations exists, and the prospects were promising enough to further elucidate the pathophysiology of depressive illness.

Episodes of depression have been characterized by an increase in levels of various markers of inflammation, centrally and peripherally (14). In addition, cellular components of the immune system have demonstrated increased activity in certain classes of cells and decreases in others (15-17). Natural killer cells have been found to be reduced with augmented IL-6 release during depressive episodes $(18,19)$. Serum levels of IL-6 and tumor necrosis factor (TNF) have been reported to be higher in depressed subjects when compared with non-depressed subjects (20). Furthermore, it has been stated that the three pro-inflammatory cytokines, IL-6, TNF and IL-1 $\beta$ are implicated in the pathophysiology of depressive illness (21). IL-6 has been proposed to be central in the systemic consequences of psychological stress, mediating with stress through the hypothalamic-pituitary-adrenal (HPA) axis and catecholamines leading to insulin resistance, coagulation abnormalities and endothelial dysfunction (22-24). Similarly, depression has been associated with systemic diseases involving induction of a pro-inflammatory state or upregulation of inflammatory markers. For example, levels of IL-6 have been found to increase with age (25) and be associated with cognitive wellbeing (26). In addition, depression caused an increase in fatty lesions in arteries in a mouse model, providing a potential link between psychological stress and vascular diseases (27). Chronic unpredictable stress was noted to induce a decrease in locomotor activity (depressive-like behavior), as well as favor atherosclerosis through activating various markers of inflammation, including $\mathrm{C}$-reactive proteins, IL-6 and elevated concentrations of vascular cell adhesion molecule 1 and intercellular adhesion molecule 1 in the plaques and plasma of apolipoprotein knockout mice (28). Levels of positive acute phase proteins were found to be increased while negative acute phase proteins were decreased during an episode of depression, implying that depression initiates an inflammatory response in the body (29). Social stress in humans has been found to trigger an increase in the circulating levels of IL-6, eventually resulting in activation of the HPA axis and its metabolic consequences, such as diabetes mellitus and coronary heart disease (30). IL-6 was observed to be increased in the plasma and cerebrospinal fluid (CSF) of patients with post-traumatic stress disorder (31). Inflammatory changes have also consistently been reported with exposure to short durations of stress. Acute stress has been associated with an increase in the levels of IL-1 $\beta$ in rats (32). In addition, acutely depressed and previously unmedicated patients were found to have higher concentrations of pro-inflammatory cytokine, IL-1 $\beta$ in the CSF (33).

A DNA microarray analysis of the aging brain demonstrated a gene expression profile suggestive of a marked inflammatory response, oxidative stress and reduced neural plasticity and neurotrophic support (34). In this analysis half of those genes upregulated with age were found to be associated with inflammatory mediators.

HPA axis hyperactivity is the hallmark of major depression and accounts for the alterations in the immune system. A study, involving 16 females suffering major depression and 16 control subjects, found that the basal concentration of cortisol was significantly higher in depressed subjects than control subjects (35). Thus, central and peripheral inflammatory parameters have been documented to be associated with mood alterations.

\section{Inflammatory cytokine concentration in depression}

Cytokines are known to cause changes in the central nervous system when injected peripherally, as well as when secreted internally in response to various conditions, such as an endotoxin challenge or in a model of stress. Previous studies have investigated the concentration of pro- and anti-inflammatory cytokines in various models of depression. Pro-inflammatory cytokine, IL-1 $\beta$ has been found to be increased in depressed elderly subjects (age, $>60$ years), directly proportional to the severity of illness (36). In another study, IL-1 $\beta$ levels were found to be higher in women with symptoms of depression when compared with those who did not have any such symptoms 1 month post-partum (37). These statistics are, however, refuted by Ovaskainen et al (38) who observed that the concentration of IL-1 $\beta$ was not increased during an episode of depression. They observed an increase in the level of IL-1 receptor antagonists (IL-1 RA). Reduced levels of zinc during an episode of depression has been proposed to originate from increased levels of 
IL-1, which results in sequestration of metallothionen, the zinc-binding protein found in the liver (39). An age-associated increase in IL- $1 \beta$ concentration and signaling was also accompanied by a similar decrease in concentration and signaling of anti-inflammatory cytokine, IL-4 (40). A recent study has reported that overexpressed inflammatory parameters are associated with suicidal ideation (41).

Conversely, anti-inflammatory cytokines modulate the initiation of depressive-like behavior in experimental animals. IL-10 knockout mice showed decreased latency to immobility in a forced swim test where administration of IL-10 was able to reverse behavior of helplessness (42). IL-10 receptor 1 is located on rat microglia, and responds to inflammatory stimuli, such as lipopolysaccharide (LPS) injection (43). It inhibits pro-inflammatory cytokine production by glial cells stimulated by LPS in a dose-dependent manner (44).

\section{Data regarding the role of IL-1ß in the pathophysiology of depression}

Aging has a significant effect on brain function. Comparisons between two human brain tissue samples showed that microglia in the aged brain (68 years-old) were markedly different from those in the young brain (34 years-old). Changes occurred in the aged brain were dystrophic and characterized by loss of fine cytoplasmic processes, appearance of swellings, and twisted and shortened processes and pyknotic nuclei. The changes are described as senescence of microglia that may account for cognitive dysfunction in the ageing brain (45). Serum concentration of IL-1 $\beta$ was found to be increased with age. Prolonged depressive-like behavior has been documented in aged rats exposed to Bacillus Calmette-Guérin $(42,46)$. As depression occurring in the later stages of life may present a different pathophysiological picture than that which occurs in younger age groups (47), an insight into the factors affecting IL-1 $\beta$ may lead to novel strategies for establishing a treatment plan.

\section{Effects of IL-1ß on neurogenesis}

Neurogenesis is the birth of neurons in the dentate gyrus of the adult brain, which continues throughout life. An important aspect of neuroplastic changes during depression is the decrease in neurogenesis along with a reduction in the size of the hippocampus (48). A study investigating antineurogenic and anhedonic effects of stress found that many of these actions require IL-1 $\beta$ as the mediator and were not observed in the presence of an IL-1 $\beta$ antagonist (49). This study observed the following: i) A decrease in hippocampal cell proliferation under the influence of IL-1 $\beta$ that was abated by its antagonist; ii) blockade of the acute stress-induced decrease in neurogenesis, as well as antineurogenic and anhedonic effects of chronic unpredictable stress by the application of a potent antagonist of said cytokine; and iii) a significant decrease in cerebral levels of interferon (IFN) $-\gamma$ and TNF- $\alpha$ in LPS-treated animals that were also injected with IL-1 RA.

\section{Role of IL-1 $\beta$ in serotonergic metabolism}

Serotonin is the most important neurotransmitter implicated in the pathophysiology of depression. The antidepressants, selective serotonin re-uptake inhibitors (SSRIs) have been developed in order to ensure the abundance of serotonin in synapses, based on the particularly dynamic association between serotonin availability and serotonin transporters, and receptor function and depression (50). In 1995, Ramamoorthy et al (51) found that IL-1 $\beta$ was a potent stimulant of the serotonin transporter in choriocarcinomatous cells and implied that experiments on nervous tissue reveal interesting data regarding its potential involvement in mood disorders. In an in vivo experiment, where LPS induced sickness behavior in mice, it also led to an increase in the extracellular concentration of 5-hydroxytryptamine and its metabolite, 5-hydroxyindoleacetic acid in the rat hippocampus. This effect was mimicked by intracerebral administration of IL-1 $\beta$ and was effectively attenuated by pre-treatment with IL-1RA (52). Recombinant human IL-1 $\beta$, administered directly into the rat hippocampus, induced sickness behavior, caused an increase in serotonergic transmission, activated the HPA axis and raised the body temperature (53). Similar increases in concentration of serotonin and catecholamines have been observed in other brain regions, namely the anterior hypothalamus of animals exposed to IL-1 $\beta$ (54). IL- $1 \beta$ and TNF- $\alpha$ have also been observed to acutely activate the serotonin transporter, SERT via p38 mitogen-activated protein kinase (MAPK), thereby increasing the uptake of serotonin, which was effectively inhibited by SB203580, the specific inhibitor of $\mathrm{p} 38$ MAPK (55). Thus, the metabolism of serotonin remains under the influence of inflammatory mediators.

\section{Receptors regulating IL-1 $\beta$ and their association with depression}

IL-1 $\beta$, a key cytokine involved in depression in the elderly, is regulated by a purinergic ATP-gated cation channel of the $\mathrm{P} 2 \mathrm{X}$ family, the $\mathrm{P} 2 \mathrm{X} 7$ receptor (56). It has repeatedly been proven to be central in post-translational modification of IL-1 $\beta$ in microglial cells upon endotoxin challenge (56). Transgenic P2X7 gene knockout mice fail to produce IL-1 when injected with LPS $(57,58)$, which also implicates its role in the eventual microglial activation and subsequent impact on behavior. Furthermore, certain single nucleotide polymorphisms that alter the function of $\mathrm{P} 2 \mathrm{X} 7$ receptors have been found to be associated with depression in humans (59). P2X7 receptor blockade has been observed to exert an antidepressant-like effect in various models of sickness behavior (60), and a P2X7 knockout mouse model demonstrated an antidepressant-like profile in behavior tests (61). Furthermore, the results of a previous study stated that IL-1 $\beta$ converting enzyme was indispensible for the depressive-like effects following intracerebral administration of LPS (62). These receptors provide more insight into the proposed association between inflammation and depression.

\section{Antidepressant therapy and variations in inflammatory cytokine concentration}

Depressive symptoms have been frequently reported in patients undergoing chemotherapy, which often leads to treatment failure (63). Increased levels of pro-inflammatory cytokines have been implicated in the depressive, as well as 
cachectic symptoms undergoing such treatment (64). Tricyclic antidepressants have been found to inhibit the release of pro-inflammatory cytokines IL- 6 , IL- $1 \beta$ and TNF- $\alpha$ in immune cells exposed to LPS (65). In another setting, a pretreatment with SSRI, paroxetine successfully prevented the onset of depressive symptoms in a significant number of patients undergoing high-dose IFN- $\alpha$ therapy for malignant melanoma as compared to those who were not pre-treated with the same antidepressant (66). IL-6 levels, found to be higher in depressed subjects, were successfully treated with antidepressant therapy, but coincided with the response to antidepressant therapy with regard to depressive symptoms. The non-responders to antidepressant therapy maintained the raised values of IL-6 (67). This evidence supports the hypothesis that the pathophysiology of depression has certain inflammatory components that should be taken into account. In addition, the idea that the efficacy of antidepressant treatment is partly influenced by inflammatory mediators requires further investigation. It should, however, be noted that inflammation does not happen in isolation. The genetic and epigenetic factors are also involved. Thus, these concepts remain complementary to the general understanding of depression pathophysiology.

\section{Depressive-like behavior induced by chemotherapy}

Anti-viral IFN- $\alpha$ therapy may induce depressive-like behavior in subjects. The incidence of these symptoms varies from 0 to $70 \%$ in different populations (68). Depression with varying severity and associated symptoms, such as insomnia, irritability, cognitive decline and suicidal ideation occur with IFN therapy (69-71). While certain studies have hypothesized that incidence of major depression remains the same in patients treated with IFN as compared to the general population (72), others indicate that major depression may be induced by the treatment, even in subjects without a previous history of major depression (73). This may lead to a cessation of treatment or reduction of dosage, which affects the course of recovery.

\section{Cytokine-associated depressive symptoms and neurodegeneration}

Numerous studiesfocusing on the association betweendepression and degenerative diseases have used pro-inflammatory cytokine levels as the basic criterion $(74,75)$. These models have been somewhat conclusive in providing the evidence that depression precedes degenerative diseases. In addition, the studies indicate that degeneration is nothing but the consequence of neuroinflammation (70-78). In one such instance, a non-toxic dose of bacterial endotoxin that resulted in increased secretion of cytokines, as well as activation of microglia, also resulted in extended loss of dopaminergic neurons to a subsequent suboptimal inflammatory stimulus (6-hydroxydopamine). This effect, however, was effectively blocked by the administration of an antagonist of IL-1 receptors (74).

\section{Neuroinflammation and its implication in the pathophysiology of depression}

The evidence of depressive symptoms following cerebrovascular lesions is varied. The prevalence of major depression ranges from 18 to $61 \%$ in stroke patients, which is a 3 -fold increase when compared with the general population (75). This association has been reported frequently $(76,77)$. Patients with pre-existing depression have been identified to exhibit greater neurological impairment following a stroke, and stroke sufferers demonstrated a higher prevalence of depression at 6 months and 1 year following a stroke when compared with the general population (78).

Patients with depression are stated to have frequent hyperintensities of white matter observed on magnetic resonance imaging scans. The presence of white matter hyperintensities is associated with a prolonged course of depressive illness. The presence of these hyperintensities is also associated with weakened effect of antidepressant treatment, as well as long-term disability and neuro-cognitive decline (79). While the inflammatory response around the site of stroke is a well-known clinical observation (80) an animal model of focal ischemia demonstrated that inflammation extends far beyond the original site of ischemic injury, predominantly mediated by microglia (81). This is exactly the same manner by which stress has been attributed to the cause of neuroinflammation in various animal models (82), which has led to formulation of a neuroinflammatory hypothesis of depressive illness (83).

\section{Conclusion}

Depression is undoubtedly a multidimensional disorder. In addition to stress as the most important cause of depression, other disease processes are increasingly being implicated in the depression pathophysiology. Age-associated accumulation of inflammatory insults may support the role of disease processes in behavioral alterations. IL-1 $\beta$ exerts a multilayered effect on determinants of behavior, and understanding the role of IL-1 $\beta$ in the pathophysiology of depression may facilitate the elucidation of its effect on alterations in amine metabolism, neurogenesis and neuroinflammation. In addition, genetic and epigenetic phenomena may be taken into account when establishing a comprehensive treatment approach.

\section{References}

1. Mathers CD and Loncar D: Projections of global mortality and burden of disease from 2002 to 2030. PLoS Med 3: e442, 2006.

2. Seligman ME and Csikszentmihalyi M: Positive psychology: an introduction. Springer Netherlands, Dordrecht, pp279-298, 2014.

3. Murphy DL, Cohen RM, Siever LJ, Roy B, Karoum F, Wyatt RJ, Garrick NA and Linnoila M: Clinical and laboratory studies with selective monoamine-oxidase-inhibiting drugs. Implications for hypothesized neurotransmitter changes associated with depression and antidepressant drug effects. Mod Probl Pharmacopsychiatry 19: 287-303, 1983.

4. Ader R and Cohen N: High time for psychoimmunology. Nature 315: 103-104, 1985.

5. Maes M: Evidence for an immune response in major depression: A review and hypothesis. Prog Neuropsychopharmacol Biol Psychiatry 19: 11-38, 1995.

6. Maes M, Berk M, Goehler L, Song C, Anderson G, Gałecki P and Leonard B: Depression and sickness behavior are Janus-faced responses to shared inflammatory pathways. BMC Med 10: 66, 2012.

7. Skaper SD, Facci L and Giusti P: Neuroinflammation, microglia and mast cells in the pathophysiology of neurocognitive disorders: a review. CNS Neurol Disord Drug Targets 13: 1654-1666, 2014.

8. Maes M, Van de Vyvere J, Vandoolaeghe E, Bril T, Demedts P, Wauters A and Neels H: Alterations in iron metabolism and the erythron in major depression: Further evidence for a chronic inflammatory process. J Affect Disord 40: 23-33, 1996. 
9. Smith RS: The macrophage theory of depression. Med Hypotheses 35: 298-306, 1991.

10. Patel A: Review: The role of inflammation in depression. Psychiatr Danub 25 (Suppl 2): S216-S223, 2013.

11. Dantzer R: Cytokine, sickness behavior, and depression Immunol Allergy Clin North Am 29: 247-264, 2009.

12. Hart BL: Biological basis of the behavior of sick animals Neurosci Biobehav Rev 12: 123-137, 1988.

13. Kent S, Bluthe RM, Dantzer R, Hardwick AJ, Kelley KW, Rothwell NJ and Vannice JL: Different receptor mechanisms mediate the pyrogenic and behavioral effects of interleukin 1. Proc Natl Acad Sci USA 89: 9117-9120, 1992.

14. Raison CL, Capuron L and Miller AH: Cytokines sing the blues: Inflammation and the pathogenesis of depression. Trends Immunol 27: 24-31, 2006.

15. Irwin M: Immune correlates of depression. Adv Exp Med Biol 461: 1-24, 1999.

16. Cruess DG, Douglas SD, Petitto JM, Have TT, Gettes D, Dubé B Cary $\mathrm{M}$ and Evans DL: Association of resolution of major depression with increased natural killer cell activity among HIV-seropositive women. Am J Psychiatry 162: 2125-2130, 2005.

17. Evans DL, Ten Have TR, Douglas SD, Gettes DR, Morrison M, Chiappini MS, Brinker-Spence P, Job C, Mercer DE, Wang YL, et al: Association of depression with viral load, CD8 T lymphocytes, and natural killer cells in women with HIV infection. Am J Psychiatry 159: 1752-1759, 2002.

18. Pike JL and Irwin MR: Dissociation of inflammatory markers and natural killer cell activity in major depressive disorder. Brain Behav Immun 20: 169-174, 2006.

19. Papanicolaou DA, Wilder RL, Manolagas SC and Chrousos GP The pathophysiologic roles of interleukin-6 in human disease. Ann Intern Med 128: 127-137, 1998.

20. Liu Y, Ho RC and Mak A: Interleukin (IL)-6, tumour necrosis factor alpha $(\mathrm{TNF}-\alpha)$ and soluble interleukin-2 receptors (sIL-2R) are elevated in patients with major depressive disorder: A meta-analysis and meta-regression. J Affect Disord 139: 230-239, 2012

21. Brebner K, Hayley S, Zacharko R, Merali Z and Anisman H: Synergistic effects of interleukin-1 $\beta$, interleukin-6, and tumor necrosis factor- $\alpha$ : Central monoamine, corticosterone, and behavioral variations. Neuropsychopharmacology 22: 566-580, 2000.

22. Yudkin JS, Kumari M, Humphries SE and Mohamed-Ali V: Inflammation, obesity, stress and coronary heart disease: Is interleukin-6 the link? Atherosclerosis 148: 209-214, 2000.

23. Carvalho LA, Urbanova L, Hamer M, Hackett RA, Lazzarino AI and Steptoe A: Blunted glucocorticoid and mineralocorticoid sensitivity to stress in people with diabetes. Psychoneuroendocrinology 51: 209-218, 2015.

24. McInnis CM, Thoma MV, Gianferante D, Hanlin L, Chen X, Breines JG, Hong S and Rohleder N: Measures of adiposity predict interleukin- 6 responses to repeated psychosocial stress Brain Behav Immun 42: 33-40, 2014.

25. Ershler WB and Keller ET: Age-associated increased interleukin- 6 gene expression, late-life diseases, and frailty. Annu Rev Med 51: 245-270, 2000.

26. Windham BG, Simpson BN, Lirette S, Bridges J, Bielak L, Peyser PA, Kullo I, Turner S, Griswold ME and Mosley TH: Associations between inflammation and cognitive function in African Americans and European Americans. J Am Geriatr Soc 62: 2303-2310, 2014

27. Huber SA, Sakkinen P, Conze D, Hardin N and Tracy R: Interleukin-6 exacerbates early atherosclerosis in mice. Arterioscler Thromb Vasc Biol 19: 2364-2367, 1999.

28. Zhang T, Chen Y, Liu H, Zhou Z, Zhai Y and Yang J: Chronic unpredictable stress accelerates atherosclerosis through promoting inflammation in apolipoprotein $\mathrm{E}$ knockout mice. Thromb Res 126: 386-392, 2010.

29. Song C, Dinan T and Leonard BE: Changes in immunoglobulin, complement and acute phase protein levels in the depressed patients and normal controls. J Affect Disord 30: 283-288, 1994.

30. Yudkin JS, Yajnik CS, Mohamed-Ali V and Bulmer K: High levels of circulating proinflammatory cytokines and leptin in urban, but not rural, Indians. A potential explanation for increased risk of diabetes and coronary heart disease. Diabetes Care 22: 363-364, 1999.

31. Baker DG, Ekhator NN, Kasckow JW, Hill KK, Zoumakis E, Dashevsky BA, Chrousos GP and Geracioti TD Jr: Plasma and cerebrospinal fluid interleukin-6 concentrations in posttraumatic stress disorder. Neuroimmunomodulation 9: 209-217, 2001
32. Nguyen KT, Deak T, Owens SM, Kohno T, Fleshner M, Watkins LR and Maier SF: Exposure to acute stress induces brain interleukin-1 $\beta$ protein in the rat. J Neurosci 18: 2239-2246, 1998.

33. Levine J, Barak Y, Chengappa KN, Rapoport A, Rebey M and Barak V: Cerebrospinal cytokine levels in patients with acute depression. Neuropsychobiology 40: 171-176, 1999.

34. Prolla TA: DNA microarray analysis of the aging brain. Chem Senses 27: 299-306, 2002

35. Choi SH and Suh KY: Interleukin-1 beta,-2,-6 production, serum concentration and hypothalamic-pituitary-adrenal axis in patients with major depression. J Korean Neuropsychiatr Assoc 37: 537-547, 1998.

36. Thomas AJ, Davis S, Morris C, Jackson E, Harrison R and O'Brien JT: Increase in interleukin-1 $\beta$ in late-life depression. Am J Psychiatry 162: 175-177, 2005.

37. Corwin EJ, Johnston N and Pugh L: Symptoms of postpartum depression associated with elevated levels of interleukin-1 beta during the first month postpartum. Biol Res Nurs 10: 128-133, 2008.

38. Ovaskainen Y,KoponenH,JokelainenJ,Keinänen-KiukaanniemiS, Kumpusalo E and Vanhala M: Depressive symptomatology is associated with decreased interleukin-1 beta and increased interleukin-1 receptor antagonist levels in males. Psychiatry Res 167: 73-79, 2009

39. Cousins RJ and Leinart AS: Tissue-specific regulation of zinc metabolism and metallothionein genes by interleukin 1 . FASEB J 2: 2884-2890, 1988

40. Nolan Y, Maher FO, Martin DS, Clarke RM, Brady MT, Bolton AE, Mills KH and Lynch MA: Role of interleukin-4 in regulation of age-related inflammatory changes in the hippocampus. J Biol Chem 280: 9354-9362, 2005.

41. O'Donovan A, Rush G, Hoatam G, Hughes BM, McCrohan A, Kelleher C, O'Farrelly C and Malone KM: Suicidal ideation is associated with elevated inflammation in patients with major depressive disorder. Depress Anxiety 30: 307-314, 2013

42. Mesquita AR, Correia-Neves M, Roque S, Castro AG, Vieira P, Pedrosa J, Palha JA and Sousa N: IL-10 modulates depressive-like behavior. J Psychiatr Res 43: 89-97, 2008

43. Ledeboer A, Brevé JJ, Wierinckx A, van der Jagt S, Bristow AF, Leysen JE, Tilders FJ and Van Dam AM: Expression and regulation of interleukin-10 and interleukin-10 receptor in rat astroglial and microglial cells. Eur J Neurosci 16: 1175-1185, 2002.

44. Ledeboer A, Brevé JJ, Poole S, Tilders FJ and Van Dam AM Interleukin-10, interleukin-4, and transforming growth factor- $\beta$ differentially regulate lipopolysaccharide-induced production of pro-inflammatory cytokines and nitric oxide in co-cultures of rat astroglial and microglial cells. Glia 30: 134-142, 2000.

45. Streit WJ, Sammons NW, Kuhns AJ and Sparks DL: Dystrophic microglia in the aging human brain. Glia 45: 208-212, 2004.

46. Kelley KW, O'Connor JC, Lawson MA, Dantzer R, Rodriguez-Zas SL and McCusker RH: Aging leads to prolonged duration of inflammation-induced depression-like behavior caused by Bacillus Calmette-Guérin. Brain Behav Immun 32 63-69, 2013.

47. Isingrini E, Desmidt T, Belzung $\mathrm{C}$ and Camus V: Endothelial dysfunction: A potential therapeutic target for geriatric depression and brain amyloid deposition in Alzheimer's disease? Curr Opin Investig Drugs 10: 46-55, 2009.

48. Rotheneichner P, Lange S, O'Sullivan A, Marschallinger J, Zaunmair P, Geretsegger C, Aigner L and Couillard-Despres S: Hippocampal neurogenesis and antidepressive therapy: shocking relations. Neural Plast 2014: 723915, 2014.

49. Koo JW and Duman RS: IL- $1 \beta$ is an essential mediator of the antineurogenic and anhedonic effects of stress. Proc Natl Acad Sci USA 105: 751-756, 2008.

50. Samuels BA, Mendez-David I, Faye C, David SA, Pierz KA, Gardier AM, Hen R and David DJ: Serotonin 1A and serotonin 4 receptors: Essential mediators of the neurogenic and behavioral actions of antidepressants. Neuroscientist 22: 26-45, 2016.

51. Ramamoorthy S, Ramamoorthy JD, Prasad PD, Bhat GK, Mahesh VB, Leibach FH and Ganapathy V: Regulation of the human serotonin transporter by interleukin-1 $\beta$. Biochem Biophys Res Commun 216: 560-567, 1995.

52. Linthorst AC, Flachskamm C, Müller-Preuss P, Holsboer F and Reul JM: Effect of bacterial endotoxin and interleukin-1 beta on hippocampal serotonergic neurotransmission, behavioral activity, and free corticosterone levels: An in vivo microdialysis study. J Neurosci 15: 2920-2934, 1995. 
53. Linthorst AC, Flachskamm C, Holsboer F and Reul JM: Local administration of recombinant human interleukin-1 beta in the rat hippocampus increases serotonergic neurotransmission, hypothalamic-pituitary-adrenocortical axis activity, and body temperature. Endocrinology 135: 520-532, 1994.

54. Shintani F, Kanba S, Nakaki T, Nibuya M, Kinoshita N, Suzuki E, Yagi G, Kato R and Asai M: Interleukin-1 beta augments release of norepinephrine, dopamine, and serotonin in the rat anterior hypothalamus. J Neurosci 13: 3574-3581, 1993.

55. Zhu CB, Blakely RD and Hewlett WA: The proinflammatory cytokines interleukin-1beta and tumor necrosis factor-alpha activate serotonin transporters. Neuropsychopharmacology 31 : 2121-2131, 2006.

56. Sperlágh B, Vizi ES, Wirkner K and Illes P: P2X7 receptors in the nervous system. Prog Neurobiol 78: 327-346, 2006.

57. Clark AK, Staniland AA, Marchand F, Kaan TK, McMahon SB and Malcangio M: P2X7-dependent release of interleukin-1 $\beta$ and nociception in the spinal cord following lipopolysaccharide. J Neurosci 30: 573-582, 2010.

58. Seil M, El Ouaaliti M, Abdou Foumekoye S, Pochet S and Dehaye JP: Distinct regulation by lipopolysaccharides of the expression of interleukin- $1 \beta$ by murine macrophages and salivary glands. Innate Immun 18: 14-24, 2012.

59. Roger S, Mei ZZ, Baldwin JM, Dong L, Bradley H, Baldwin SA, Surprenant A and Jiang LH: Single nucleotide polymorphisms that were identified in affective mood disorders affect ATP-activated P2X7 receptor functions. J Psychiatr Res 44: 347-355, 2010

60. Andó R, Gölöncsér F and Sperlágh B: Modulation of P2X7 receptor function alters depressive behavior in rodent models of depression. Front Neurosci Conference Abstract: IBRO International Workshop 2010, 2010.

61. Basso AM, Bratcher NA, Harris RR, Jarvis MF, Decker MW and Rueter LE: Behavioral profile of $\mathrm{P} 2 \mathrm{X} 7$ receptor knockout mice in animal models of depression and anxiety: Relevance for neuropsychiatric disorders. Behav Brain Res 198: 83-90, 2009.

62. Lawson MA, McCusker RH and Kelley KW: Interleukin-1 beta converting enzyme is necessary for development of depression-like behavior following intracerebroventricular administration of lipopolysaccharide to mice. J Neuroinflammation 10: 54, 2013.

63. Leutscher PDC, Lagging M, Buhl MR, Pedersen C, Norkrans G, Langeland N, Mørch K, Färkkilä M, Hjerrild S, Hellstrand K, et al; NORDynamIC Group: Evaluation of depression as a risk factor for treatment failure in chronic hepatitis C. Hepatology 52: $430-435,2010$

64. Illman J, Corringham R, Robinson D Jr, Davis HM, Rossi JF, Cella D and Trikha M: Are inflammatory cytokines the common link between cancer-associated cachexia and depression? J Support Oncol 3: 37-50, 2005.

65. Xia Z, DePierre JW and Nässberger L: Tricyclic antidepressants inhibit IL-6, IL-1 $\beta$ and TNF- $\alpha$ release in human blood monocytes and IL-2 and interferon- $\gamma$ in T cells. Immunopharmacology 34 27-37, 1996.

66. Musselman DL, Lawson DH, Gumnick JF, Manatunga AK, Penna S, Goodkin RS, Greiner K, Nemeroff CB and Miller AH: Paroxetine for the prevention of depression induced by high-dose interferon alfa. N Engl J Med 344: 961-966, 2001.

67. Lanquillon S, Krieg JC, Bening-Abu-Shach U and Vedder $\mathrm{H}$ : Cytokine production and treatment response in major depressive disorder. Neuropsychopharmacology 22: 370-379, 2000.
68. Trask PC, Esper P, Riba M and Redman B: Psychiatric side effects of interferon therapy: Prevalence, proposed mechanisms, and future directions. J Clin Oncol 18: 2316-2326, 2000

69. Yates WR and Gleason O: Hepatitis C and depression. Depress Anxiety 7: 188-193, 1998.

70. Scheibel RS, Valentine AD, O'Brien S and Meyers CA: Cognitive dysfunction and depression during treatment with interferon-alpha and chemotherapy. J Neuropsychiatry Clin Neurosci 16: 185-191, 2004

71. Gitlin N: Hepatitis B: Diagnosis, prevention, and treatment. Clin Chem 43: 1500-1506, 1997.

72. Horsmans Y: Chronic hepatitis C, depression and interferon. J Hepatol 42: 788-789, 2005.

73. Lotrich FE, Rabinovitz M, Gironda P and Pollock BG: Depression following pegylated interferon-alpha: Characteristics and vulnerability. J Psychosom Res 63: 131-135, 2007.

74. Koprich JB, Reske-Nielsen C, Mithal P and Isacson O: Neuroinflammation mediated by IL-1 $\beta$ increases susceptibility of dopamine neurons to degeneration in an animal model of Parkinson's disease. J Neuroinflammation 5: 8, 2008.

75. Sulaiman AH, Zainal NZ, Tan KS and Tan CT: Prevalence and associations of post-stroke depression. Neurol J Southeast Asia 7: 71-75, 2002.

76. Broomfield NM, Quinn TJ, Abdul-Rahim AH, Walters MR and Evans JJ: Depression and anxiety symptoms post-stroke/TIA: Prevalence and associations in cross-sectional data from a regional stroke registry. BMC Neurol 14: 198, 2014.

77. Ojagbemi A, Owolabi M, Atalabi M and Baiyewu O: Stroke lesions and post-stroke depression among survivors in Ibadan, Nigeria. Afr J Med Med Sci 42: 245-251, 2013.

78. Herrmann N, Black SE, Lawrence J, Szekely C and Szalai JP: The Sunnybrook Stroke Study: A prospective study of depressive symptoms and functional outcome. Stroke 29: 618-624, 1998

79. Herrmann LL, Le Masurier M and Ebmeier KP: White matter hyperintensities in late life depression: A systematic review. J Neurol Neurosurg Psychiatry 79: 619-624, 2008.

80. Huang J, Upadhyay UM and Tamargo RJ: Inflammation in stroke and focal cerebral ischemia. Surg Neurol 66: 232-245, 2006.

81. Wiart M, Davoust N, Pialat J-B, Desestret V, Moucharrafie S, Cho TH, Mutin M, Langlois JB, Beuf O, Honnorat J, et al: MRI monitoring of neuroinflammation in mouse focal ischemia. Stroke 38: 131-137, 2007.

82. Tynan RJ, Naicker S, Hinwood M, Nalivaiko E, Buller KM, Pow DV, Day TA and Walker FR: Chronic stress alters the density and morphology of microglia in a subset of stress-responsive brain regions. Brain Behav Immun 24: 1058-1068, 2010.

83. Maes M, Yirmyia R, Noraberg J, Brene S, Hibbeln J, Perini G, Kubera M, Bob P, Lerer B and Maj M: The inflammatory \& neurodegenerative (I\&ND) hypothesis of depression: Leads for future research and new drug developments in depression. Metab Brain Dis 24: 27-53, 2009. 